\title{
Effect of Chitosan as a Cross-Linker on Matrix Metalloproteinase Activity and Bond Stability with Different Adhesive Systems
}

\author{
Eugenia Baena $^{1}$, Sandra R Cunha ${ }^{2,3,4}$, Tatjana Maravić ${ }^{2,5}$, Allegra Comba ${ }^{2}$, \\ Federica Paganelli ${ }^{2}$, Giulio Alessandri-Bonetti ${ }^{2}$, Laura Ceballos ${ }^{1}$, Franklin R Tay ${ }^{6}$, \\ Lorenzo Breschi $^{2, *}$ and Annalisa Mazzoni ${ }^{2}$ \\ 1 Area of Stomatology, Health Sciences Faculty, King Juan Carlos University, Avda. de Atenas, \\ s/n. 28922 Alcorcón, Madrid, Spain; eugenia.baena@urjc.es (E.B.); laura.ceballos@urjc.es (L.C.) \\ 2 Department of Biomedical and Neuromotor Sciences, DIBINEM, University of Bologna, \\ Alma Mater Studiorum, Via San Vitale 59, 40125 Bologna, Italy; sandra-cunha@uiowa.edu (S.R.C.); \\ tatjana.maravic2@unibo.it (T.M.); allegra.comba@unibo.it (A.C.); paganellifederica73@gmail.com (F.P.); \\ giulio.alessandri@unibo.it (G.A.-B.); annalisa.mazzoni@unibo.it (A.M.) \\ 3 Department of Restorative Dentistry, School of Dentistry, University of São Paulo, São Paulo 14040-904, Brazil \\ 4 Department of Operative Dentistry, College of Dentistry, University of Iowa, 801 Newton Rd, \\ Iowa City, IA 52242, USA \\ 5 School of Dentistry, Faculty of Medicine, University of Novi Sad, Hajduk Veljkova 3, 21000 Novi Sad, Serbia \\ 6 Department of Endodontics, The Dental College of Georgia, Augusta University, 1430 John Wesley Gilbert \\ Drive, Augusta, GA 30912, USA; ftay@augusta.edu \\ * Correspondence: lorenzo.breschi@unibo.it; Tel.: +39-051-2088139; Fax: +39-051-225208
}

Received: 21 April 2020; Accepted: 13 May 2020; Published: 18 May 2020

check for updates

\begin{abstract}
The aim of the present study was to evaluate the effect of $0.1 \%$ chitosan (Ch) solution as an additional primer on the mechanical durability and enzymatic activity on dentine using an etch-and-rinse (E\&R) adhesive and a universal self-etch (SE) adhesive. Microtensile bond strength and interfacial nanoleakage expression of the bonded interfaces for all adhesives (with or without pretreatment with $0.1 \%$ Ch solution for $1 \mathrm{~min}$ and air-dried for $5 \mathrm{~s}$ ) were analyzed immediately and after 10,000 thermocycles. Zymograms of protein extracts from human dentine powder incubated with Optibond FL and Scotchbond Universal on untreated or Ch-treated dentine were obtained to examine dentine matrix metalloproteinase (MMP) activities. The use of $0.1 \%$ Ch solution as an additional primer in conjunction with the E\&R or SE adhesive did not appear to have influenced the immediate bond strength (T0) or bond strength after thermocycling (T1). Zymography showed a reduction in MMP activities only for mineralized and demineralized dentine powder after the application of $\mathrm{Ch}$. Application of $0.1 \% \mathrm{Ch}$ solution does not increase the longevity of resin-dentine bonds. Nonetheless, the procedure appears to be proficient in reducing dentine MMP activities within groups without adhesive treatments. Further studies are required to comprehend the cross-linking of Ch with dentine collagen.
\end{abstract}

Keywords: chitosan; matrix metalloproteinases; bond strength; cross-linkers; zymography

\section{Introduction}

Adhesion to dentine relies on the formation of the hybrid layer (HL), a structure consisting of an adhesive resin monomer-infiltrated demineralized dentine collagen matrix [1-3]. This connecting layer is the weakest link in the resin-dentine interface because collagen fibrils that are not completely infiltrated by resin are susceptible to enzymatic degradation over time [4-6]. 
The most prominent group of endogenous enzymes in dentine are the matrix metalloproteinases (MMPs). These enzymes are a family of $\mathrm{Zn}^{2+}$ - and $\mathrm{Ca}^{2+}$-dependent proteases that are present in mineralized dentine and the dentinal tubules [7-10]. Endogenous proteases are trapped by apatite crystallites in the dentine collagen matrix in non-functional forms. When exposed to a low $\mathrm{pH}$ environment, such as those created by etch-and-rinse or self-etch adhesive systems, the MMPs are exposed and converted to active functional forms [11-14]. Inhibition of collagen degradation by MMPs improves HL integrity, decreases nanoleakage, and enhances the durability of resin-dentine bonds [1,15].

Several mechanisms have been proposed to reduce HL degradation over time. The use of cross-linking agents prior to adhesive application improves collagen stiffness through the foundation of additional hydrogen bonding and/or formation of covalent intermolecular and intramolecular cross-links [1,4,16-21]. Although an extensive range of cross-linking agents are available, the specific anti-MMP effects of these agents remain obscure.

Recently, research on novel materials in the biomedical field [22-24] has shifted towards nature-derived materials (such as marine-based materials) obtained using advanced eco-friendly technologies [25]. One of the materials of interest in the field of dentistry is chitosan (Ch), a natural hydrophilic polycationic biopolymer derived from alkaline deacetylation of chitin. It is present in the shells of crustaceans and has a broad range of potential dental applications because of its biocompatibility, adhesive potential, and antibacterial properties [26-29]. Ch has been described in the literature as a biopolymer with cross-linking properties because of its large number of free hydroxyl and amino groups that form ionic complexes with collagen. Cross-linking dentine collagen with $\mathrm{Ch}$ produces a micro-fibrillar network with superior mechanical properties. These cross-linked collagen matrices also possess antimicrobial and anti-biofilm activities [28,30-32]. Incorporation of Ch into dentine adhesives apparently did not interfere with the microtensile bond strength of those adhesives to dentine; such a regime also reduced the adverse effects of ageing of the resin-dentine interface by thermo-mechanical cycling and created interfaces with antibacterial properties $[33,34]$. When $\mathrm{Ch}$ was used with riboflavin, an MMPs inhibitor, the combination improved the mechanical properties of dentine and reduced the degradation of the resin-dentine interface synergistically $[28,35]$.

Accordingly, the objective of the present study was to examine the effect of using $0.1 \%$ Ch solution as an additional primer on the bond strength of resin-bonded dentine created with a three-step etch-and-rinse adhesive or a universal self-etch adhesive. Zymography of dentine extracts was also performed to analyze the potential inhibition effect of Ch on dentine MMPs. The null hypotheses tested were that the use of $\mathrm{Ch}$ as a collagen cross-linker: (1) Has no effect on preserving the resin-dentine bond strength over time, and (2) has no effect on the inactivation of endogenous dentine MMPs.

\section{Results}

\subsection{Microtensile Bond Strength Test ( $\mu$ TBS)}

The sample preparation procedures for the different groups are reported in Table 1 . The microtensile bond strengths of the four experimental groups at T0 and T1 are shown in Table 2. Both the factors adhesive $(p<0.001)$ and time $(p<0.001)$ significantly affected the bond strength results. The interaction of these two factors was also significant $(p<0.001)$. At T0, Optibond FL (OFL) and Optibond FL with chitosan pretreatment (OFL-Ch) showed the highest $\mu$ TBS values, with no statistical differences between the two experimental subgroups. Scotchbond Universal (SBU) $\mu$ TBS was not significantly different from the $\mu$ TBS of Scotchbond Universal with chitosan pretreatment (SBU-Ch). According to these results, the use of $0.1 \% \mathrm{Ch}$ as an additional primer did not adversely affect the immediate bond strength of both adhesives immediately after bonding. At T1, all adhesives presented similar $\mu$ TBS values regardless of $\mathrm{Ch}$ pre-treatment, with no statistical differences among the four T1 experimental subgroups. After thermocycling, the bond strength of OFL and OFL-Ch decreased, differently from the SBU and SBU-Ch groups that had their $\mu$ TBS values increased. 
Table 1. Groups and clinical procedure for microtensile bond strength test.

\begin{tabular}{cl}
\hline & \multicolumn{1}{c}{ Sample Preparation } \\
\hline G1: OFL & $\begin{array}{l}\text { Dentine etching for 15 s with 37.5\% phosphoric-acid gel (Kerr, Orange, CA, USA) followed } \\
\text { by water rinsing and application of primer and bonding (Optibond FL, Kerr) following the } \\
\text { manufacturer's instructions }\end{array}$ \\
\hline G2: OFL-Ch & $\begin{array}{l}\text { Dentine etching as for G1. Pretreatment with 0.1\% Ch water-solution for 1 min and } \\
\text { air-drying for 5 s. Application of primer and bonding (Optibond FL, Kerr) following } \\
\text { manufacturer's instructions on the Ch-treated dentine. }\end{array}$ \\
\hline G3: SBU & $\begin{array}{l}\text { Scotchbond Universal (3M ESPE, St. Paul, MN, USA) application in self-etch mode on } \\
\text { mineralized dentine according to the manufacturer's instructions. }\end{array}$ \\
\hline G4: SBU-Ch & $\begin{array}{l}\text { Mineralized dentine treated with 0.1\% Ch for 1 min and air-dried for } 5 \text { s. followed by SBU } \\
\text { adhesive applied as for Group 3. }\end{array}$ \\
\hline
\end{tabular}

Table 2. Microtensile bond strengths (mean $\pm \mathrm{SD}$, in MPa) of adhesive groups with and without $\mathrm{Ch}$ immediately after bonding (T0) and after thermocycling (T1).

\begin{tabular}{ccc}
\hline & T0 & T1 \\
\hline \multirow{2}{*}{ OFL } & $41.3(14.5)^{\mathrm{Aa}}$ & $32.2(12.9)^{\mathrm{Ba}}$ \\
& $(54.1 \mathrm{~A} / 25 \mathrm{CC} / 1.4 \mathrm{CD} / 19.5 \mathrm{M})$ & $(66.7 \mathrm{~A} / 28 \mathrm{CC} / 1.3 \mathrm{CD} / 4 \mathrm{M})$ \\
\hline \multirow{2}{*}{ OFL-Ch } & $38.0(7.7)^{\mathrm{Aa}}$ & $29.2(14.1)^{\mathrm{Ba}}$ \\
& $(61.2 \mathrm{~A} / 13 \mathrm{CC} / 2.3 \mathrm{CD} / 23.5 \mathrm{M})$ & $(78.3 \mathrm{~A} / 6 \mathrm{CC} / 1.2 \mathrm{CD} / 14.5 \mathrm{M})$ \\
\hline \multirow{2}{*}{ SBU } & $25.0(16.5)^{\mathrm{Bb}}$ & $30.4(11.8)^{\mathrm{Aa}}$ \\
& $(85.2 \mathrm{~A} / 6.2 \mathrm{CC} / 1.2 \mathrm{CD} / 7.4 \mathrm{M})$ & $(61.2 \mathrm{~A} / 29.6 \mathrm{CC} / 2 \mathrm{CD} / 7.2 \mathrm{M})$ \\
\hline \multirow{2}{*}{ SBU-Ch } & $28.1(14.3)^{\mathrm{Bb}}$ & $33.1(17.0)^{\mathrm{Aa}}$ \\
& $(75.5 \mathrm{~A} / 9.6 \mathrm{CC} / 2.1 \mathrm{CD} / 12.8 \mathrm{M})$ & $(57.7 \mathrm{~A} / 27.9 \mathrm{CC} / 1.9 \mathrm{CD} / 12.5 \mathrm{M})$
\end{tabular}

For comparison among the adhesive groups with and without $\mathrm{Ch}$ for $\mathrm{T} 0$ and $\mathrm{T} 1$, different lower-case letters in the same columns are significantly different $(p<0.05)$. Different upper-case letters in the same row means a significant difference $(p<0.05)$ in the bond strength between the factor time. Percentages of the failure modes (in parentheses) were classified as: A, adhesive; $\mathrm{CC}$, cohesive in resin composite; $\mathrm{CD}$, cohesive in dentine and $\mathrm{M}$, mixed failure.

\subsection{Interfacial Nanoleakage}

The four $2 \times 4$ contingency tables depicting the nanoleakage scores from the four subgroups are shown in Tables 3-6. For OFL and OFL-Ch, the sum of the probabilities of the observed array of cell frequencies, together with the probabilities of all other cell frequency arrays that are less than or equal to the probability of the observed array (i.e., PA) for T0 is 0.0095 and for T1 0.0069 . There was a statistically significant association between the method in which the specimens were bonded and the nanoleakage score $(p<0.05)$. Nevertheless, for SBF and SBF-Ch, the probability of the observed array of cell frequencies plus the sum of the probabilities of all other cell frequency arrays are equal to or smaller than the probability of the observed array (i.e., PA) for T0 is 0.5726 and for T1 05226 . A statistically significant association between the method in which the specimens were bonded and the nanoleakage score was not found $(p>0.05)$. The percentage distribution of nanoleakage is shown in Figure 1. 
Table 3. $2 \times 4$ contingency table comparing nanoleakage distribution between OFL-T0 and OFL-Ch-T0 using the Fisher-Freeman-Halton statistic.

\begin{tabular}{|c|c|c|c|c|c|}
\hline & $0 \%-25 \%$ & $25 \%-50 \%$ & $50 \%-75 \%$ & $75 \%-100 \%$ & Total \\
\hline OFL-T0 & 6 & 3 & 1 & 0 & 10 \\
\hline OFL-Ch-T0 & 2 & 0 & 4 & 4 & 10 \\
\hline Total & 8 & 3 & 5 & 4 & 20 \\
\hline
\end{tabular}

$P_{\mathrm{A}}=0.0095$, where $P_{\mathrm{A}}$ : the probability of the observed array of cell frequencies plus the sum of the probabilities of all other cell frequency arrays (such as would be consistent with the observed marginal totals) that are equal to or smaller than the probability of the observed array. $P_{\mathrm{B}}=0.0080$, where $P_{\mathrm{B}}$ : the probability of the observed array of cell frequencies plus the sum of the probabilities of all other cell-frequency arrays (such as would be consistent with the observed marginal totals) that are smaller than the probability of the observed array. The difference in the nanoleakage distribution at time T0 between the two groups is significantly different $(p<0.05) . \mathrm{P}_{\mathrm{A}}$ and $\mathrm{P}_{\mathrm{B}}$ are both non-directional (two-tailed) probabilities. Number of tables evaluated $=112$. Note: Chi-square test was not performed on the data set because more than $20 \%$ of the cells have an expected frequency of less than 5 , and that some cells have an expected frequency smaller than 1.0.

Table 4. $2 \times 4$ contingency table comparing the nanoleakage distribution between OFL-T1 and OFL-Ch-T1 using the Fisher-Freeman-Halton statistic.

\begin{tabular}{cccccc}
\hline & $\mathbf{0} \mathbf{0 - 2 5 \%}$ & $\mathbf{2 5 \% - 5 0 \%}$ & $\mathbf{5 0} \mathbf{-}-\mathbf{7 5} \%$ & $\mathbf{7 5 \% - 1 0 0 \%}$ & Total \\
\hline OFL-T1 & 5 & 4 & 1 & 0 & 10 \\
\hline OFL-Ch-T1 & 1 & 3 & 5 & 1 & 10 \\
\hline Total & 6 & 7 & 6 & 1 & 20
\end{tabular}

$P_{\mathrm{A}}=0.0069$, where $P_{\mathrm{A}}$ : the probability of the observed array of cell frequencies plus the sum of the probabilities of all other cell frequency arrays (such as would be consistent with the observed marginal totals) that are equal to or smaller than the probability of the observed array. $P_{\mathrm{B}}=0.0062$, where $P_{\mathrm{B}}$ : the probability of the observed array of cell frequencies plus the sum of the probabilities of all other cell frequency arrays (such as would be consistent with the observed marginal totals) that are smaller than the probability of the observed array. The difference in the nanoleakage distribution at time T1 between the two groups is significantly different $(p<0.05)$. $\mathrm{P}_{\mathrm{A}}$ and $\mathrm{P}_{\mathrm{B}}$ are both non-directional (two-tailed) probabilities. Number of tables evaluated $=80$. Note: Chi-square test was not performed on the data set because more than $20 \%$ of the cells have an expected frequency of less than 5 , and that some cells have an expected frequency smaller than 1.0.

Table 5. $2 \times 4$ contingency table comparing the nanoleakage distribution between SBF-T0 and SBF-Ch-T0 using the Fisher-Freeman-Halton statistic.

\begin{tabular}{|c|c|c|c|c|c|}
\hline & $0 \%-25 \%$ & $25 \%-50 \%$ & $50 \%-75 \%$ & $75 \%-100 \%$ & Total \\
\hline SBF-T0 & 1 & 3 & 1 & 5 & 10 \\
\hline SBF-Ch-T0 & 4 & 1 & 1 & 4 & 10 \\
\hline Total & 5 & 4 & 2 & 9 & 20 \\
\hline
\end{tabular}

$P_{\mathrm{A}}=0.5726$, where $P_{\mathrm{A}}$ : the probability of the observed array of cell frequencies plus the sum of the probabilities of all other cell frequency arrays (such as would be consistent with the observed marginal totals) that are equal to or smaller than the probability of the observed array. $P_{\mathrm{B}}=0.4908$, where $P_{\mathrm{B}}$ : the probability of the observed array of cell frequencies plus the sum of the probabilities of all other cell frequency arrays (such as would be consistent with the observed marginal totals) that are smaller than the probability of the observed array. The difference in the nanoleakage distribution at time T0 between the two groups is not significantly different $(p>0.05) . \mathrm{P}_{\mathrm{A}}$ and $\mathrm{P}_{\mathrm{B}}$ are both non-directional (two-tailed) probabilities. Number of tables evaluated $=88$. Note: Chi-square test was not performed on the data set because more than $20 \%$ of the cells have an expected frequency of less than 5 , and that some cells have an expected frequency smaller than 1.0. 
Table 6. $2 \times 4$ contingency table comparing the nanoleakage distribution between SBF-T1 and SBF-Ch-T1 using the Fisher-Freeman-Halton statistic.

\begin{tabular}{|c|c|c|c|c|c|}
\hline & $0 \%-25 \%$ & $25 \%-50 \%$ & $50 \%-75 \%$ & $75 \%-100 \%$ & Total \\
\hline SBF-T1 & 2 & 5 & 3 & 0 & 10 \\
\hline SBF-Ch-T1 & 3 & 2 & 5 & 0 & 10 \\
\hline Total & 5 & 7 & 9 & 0 & 20 \\
\hline
\end{tabular}

$P_{\mathrm{A}}=0.5226$, where $P_{\mathrm{A}}$ : the probability of the observed array of cell frequencies plus the sum of the probabilities of all other cell frequency arrays (such as would be consistent with the observed marginal totals) that are equal to or smaller than the probability of the observed array. $P_{\mathrm{B}}=0.4590$, where $P_{\mathrm{B}}$ : the probability of the observed array of cell frequencies plus the sum of the probabilities of all other cell frequency arrays (such as would be consistent with the observed marginal totals) that are smaller than the probability of the observed array. The difference in the nanoleakage distribution at time T1 between the two groups is not significantly different $(p>0.05) . \mathrm{P}_{\mathrm{A}}$ and $\mathrm{P}_{\mathrm{B}}$ are both non-directional (two-tailed) probabilities. Number of tables evaluated $=42$. Note: Chi-square test was not performed on the data set because more than $20 \%$ of the cells have an expected frequency of less than 5 , and that some cells have an expected frequency smaller than 1.0.

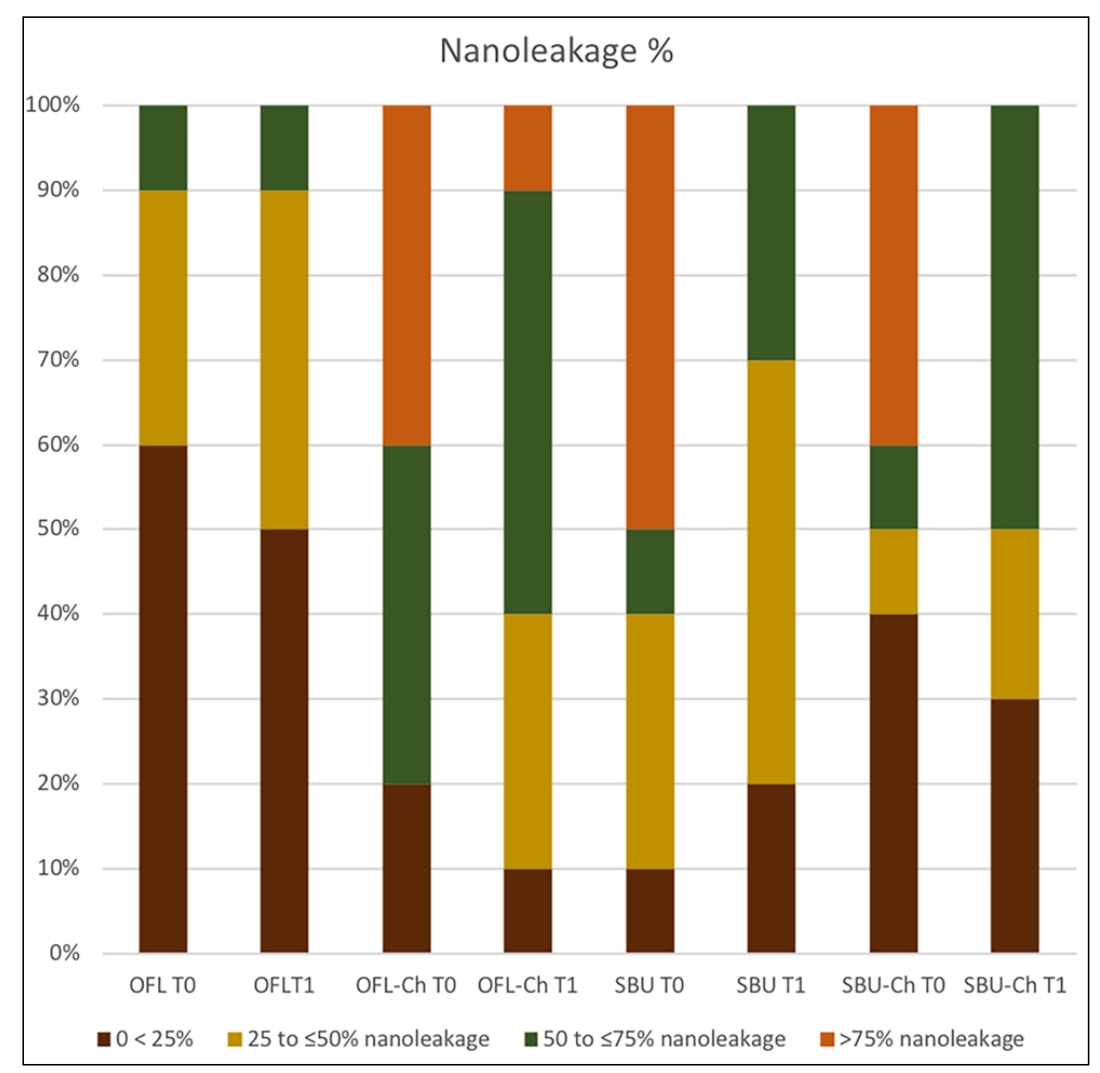

Figure 1. Distribution of the nanoleakage expression (\%) for each experimental group at times T0 and T1. OFL: Optibond FL; SBU: Scotchbond Universal; Ch.

Representative scanning electron microscopy images of the nanoleakage expression along the resin-dentine interfaces of the four experimental groups at time T0 are shown in Figure 2. The OFL (Figure 2a) and OFL-Ch (Figure 2b) groups showed dispersed silver deposition with a spotted pattern. Conversely, specimens bonded with the universal adhesive SBU exhibited more continuous and linear silver deposition along the interface together with a reticular pattern within the resin. Silver-impregnated water channels (i.e., water trees) were evident in specimens bonded with SBU regardless of $\mathrm{Ch}$ application (Figure $2 \mathrm{c}, \mathrm{d}$ ). 

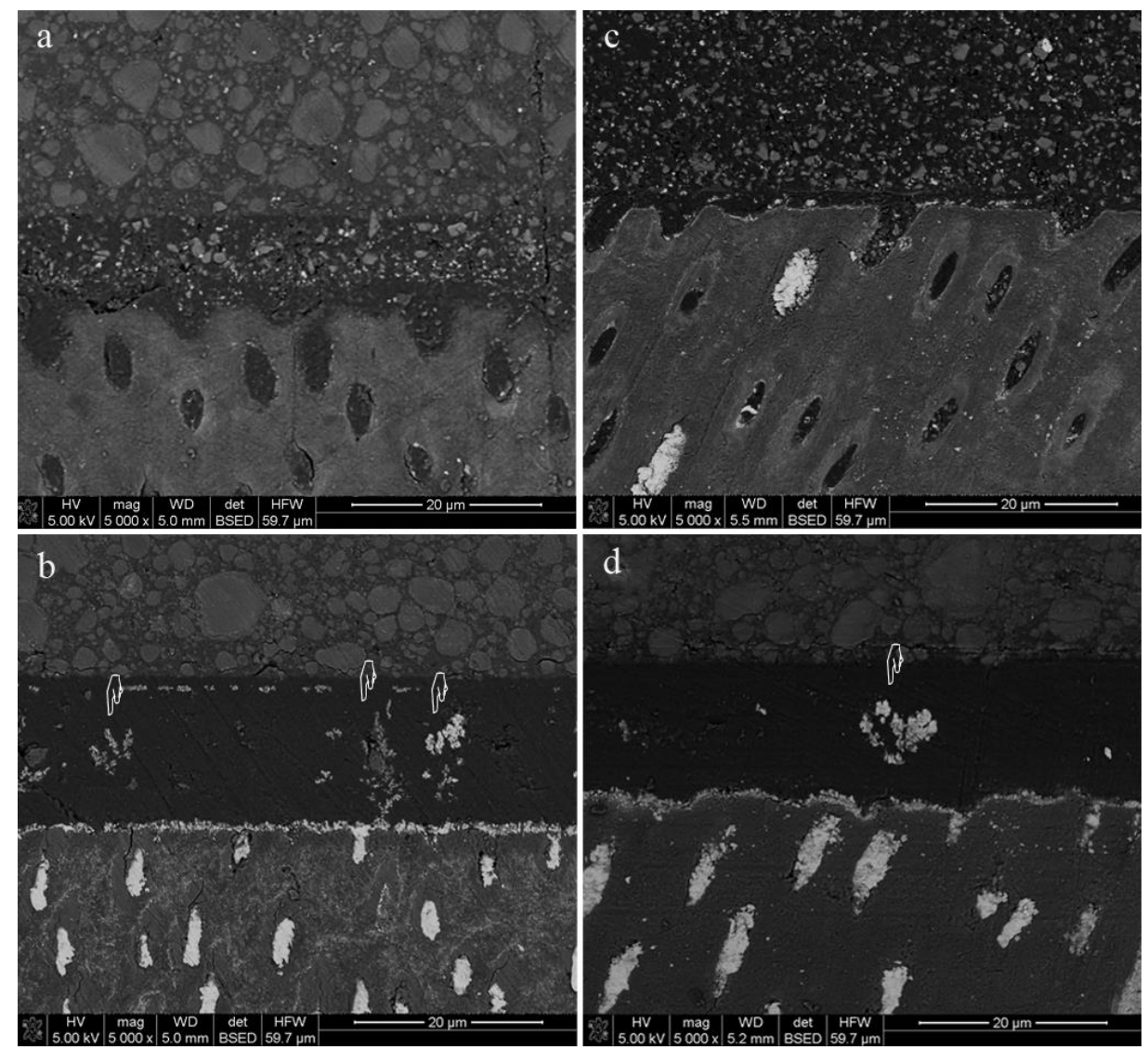

Figure 2. Scanning electron microscopy images of representative nanoleakage expression (pointers) along the resin-dentine interface created by different adhesives in the presence or absence of $\mathrm{Ch}$ pretreatment. OFL: Optibond FL; SBU: Scotchbond Universal. (a) OFL at time T0. (b) OFL-Ch at time T0. A spotted pattern was identified for these experimental subgroups. (c) SBU at time T0. (d) SBU-Ch at time T0. A more defined linear nanoleakage pattern was observed for these subgroups. Silver depositions were more continuous and water channels (i.e., water channels; pointers) were detected within the adhesive layers.

\subsection{Zymography}

Bands around 72, 67, and $92 \mathrm{kDa}$, corresponding to the molecular weight of the pro- and active form of MMP-2 and pro-MMP-9, respectively, were present in the positive control (MP), along with an additional band around $45 \mathrm{kDa}$ that might represent the degradation products of MMP-2 or MMP-9 (Figure 3, lane 2) [36]. Incubation of mineralized dentine with $0.1 \% \mathrm{Ch}(\mathrm{MP}+\mathrm{Ch})$ inactivated the enzymatic activities completely (Figure 3, lane 3).

Gelatinolytic activities were also detected in the demineralized dentine powder, with increases in MMP-2 and pro-MMP-9 expression, when compared to the mineralized dentine powder (Figure 3, lane 4). After the incubation of demineralized dentine powder with $0.1 \% \mathrm{Ch}$, the expression of pro-MMP-2 and pro-MMP-9 decreased and MMP-2 was no longer detectable (Figure 3, lane 5).

Application of the etch-and-rinse adhesive OFL to $10 \%$ phosphoric acid-etched dentine powder (Figure 3, lane 6) and pretreatment of the acid-etched dentine powder with Ch prior to OFL application (Figure 3, lane 7) activated MMP-2 and MMP-9, with the appearance of the active form of MMP-9 at $86 \mathrm{kDa}$ [36]. When mineralized dentine powder was treated with the universal adhesive SBU in self-etch mode, pro-MMP-9, MMP-2, and a band around $50 \mathrm{kDa}$ were detected in the zymogram (Figure 3, lane 8). Pretreatment of the mineralized dentine powder with $0.1 \% \mathrm{Ch}$ prior to the application of SBU in the self-etch mode did not influence the enzymatic activity (Figure 3, lane 9). 


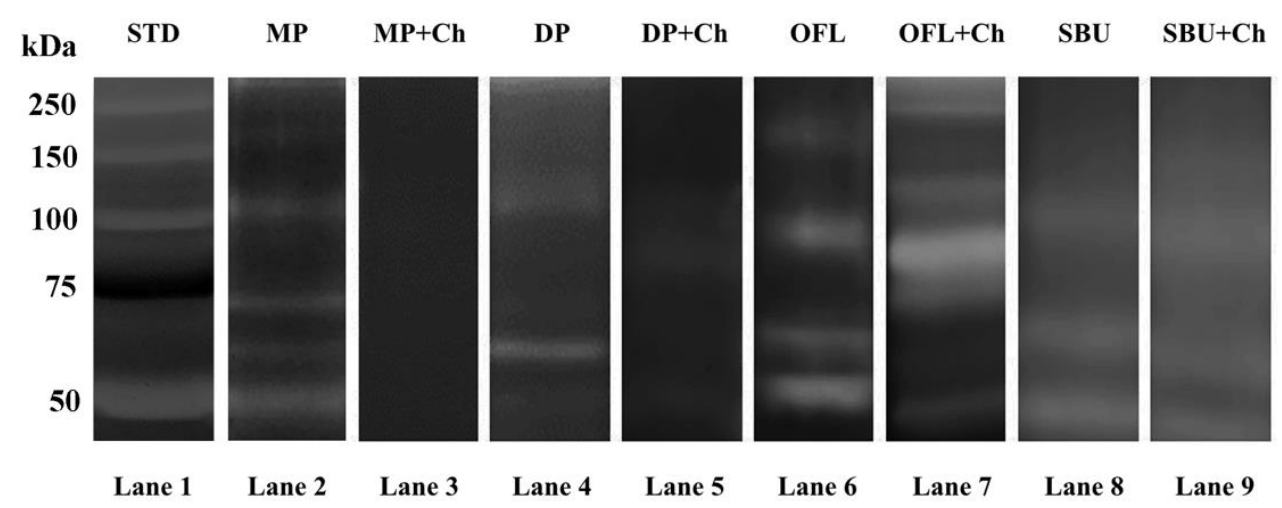

Figure 3. Zymography of extracts obtained from dentine powder treated with the two adhesives with or without Ch pre-treatment. Lane 1: Standards (Std) in kDa. Lane 2: mineralized dentine powder (MP). Lane 3: mineralized dentine powder after incubation with $\mathrm{Ch}$. Lane 4: dentine powder demineralized with $10 \%$ phosphoric acid (DP). Lane 5: demineralized dentine powder treated with $\mathrm{Ch}$. Lane 6: demineralized dentine powder treated with OFL. Lane 7: demineralized dentine powder incubated with Ch followed by OFL adhesive application. Lane 8: mineralized dentine powder incubated with Ch followed by SBU adhesive application. Lane 9: mineralized dentine powder incubated with $\mathrm{Ch}$ followed by SBU adhesive application.

\section{Discussion}

The present study used a $0.1 \%$ Ch solution as an additional primer before dentine bonding procedures. Application of $\mathrm{Ch}$ before bonding with an etch-and-rinse adhesive or a self-etch adhesive to dentine did not result in better preservation of the $\mu$ TBS immediately as well as after thermocycling. Thus, the first null hypothesis that "the use of $\mathrm{Ch}$ as a collagen cross-linker has no effect on bond strength deterioration over time" cannot be rejected. Based on the results derived from zymography of the dentine powder extracts, the use of $0.1 \%$ Ch solution decreased the enzymatic activity of MMPs in some groups. Thus, the second null hypothesis that "Ch as a collagen cross-linker has no effect on inactivation of endogenous dentine MMPs" has to be partially rejected.

The use of aldehydes, such as glutaraldehyde or acrolein, as cross-linking agents for demineralized dentine collagen matrices has been reported previously [20,37-39]. The aldehyde group increases the strength of collagen by chemically interacting with its amino groups, thereby minimizing the degradation of the adhesive interface. Despite the effectiveness of aldehydes in preserving the HL, they cannot be used clinically because of their extreme cytotoxicity caused by depolymerization $[1,40,41]$.

The use of natural less toxic polymers for dentine pre-treatment, such as $\mathrm{Ch}$, has recently been studied $[4,33,34,42]$. Previous reports stated that the incorporation [34] of this polymer within an adhesive did not influence the immediate bond strength. Conversely, the addition of Ch conferred additional benefits, such as antibacterial activity or delayed thermo-mechanical ageing [33,34]. Similarly, results from the present study indicate that the immediate and thermocycled bond strengths of the adhesives tested were not adversely affected by the use of $\mathrm{Ch}$ for dentine pre-treatment. It is interesting that the effect of thermocycling is adhesive dependent; the tbond strengths of the OFL and OFL-Ch experimental groups decreased while those of the SBU and SBU-Ch groups increased at T1.

The difference between the bond strengths of the etch-and-rinse and self-etch adhesives has already been discussed in the literature. Potential clinical errors may arise upon the use of phosphoric acid-etching because of the need to rinse off the etchant and the difficulty in managing dentine moisture during the application of etch-and-rinse adhesives. Self-etch adhesives containing 10-methacryloyloxydecyl dihydrogen phosphate, such as SBU, anecdotally provides a more stable chemical bond to dentine over the course of time [43-45]. Deposition of stable 10-MDP-Ca salt in Hydroxyethylmethacrylate (HEMA)-free adhesives [46], via the formation of a nanolayer at the adhesive interface formed by this monomer, conceptually increases the interfacial mechanical strength $[45,47,48]$. Unfortunately, nanolayering of 10-MDP-Ca salt is rarely identified in resin-dentine interfaces created by 
contemporary 10-MDP-containing adhesives [49] and the incorporation of 10-MDP in adhesives does not contribute to the durability of resin-dentine bonds [50]. Conversely, interfacial stress relaxation via hygroscopic expansion of the overlying composite may produce an increase in the bond strength over a certain period of time [51]. Self-etch adhesives, which are acidic in nature, require a relatively longer time to achieve adequate degrees of conversion [51,52]. Such a phenomenon provides rational justification of the higher bond strengths values observed in the SBU groups after thermocycling.

Nanoleakage examination identified nanometre-sized defects within the resin-dentine interface that increased with ageing $[53,54]$. These defects represent water-rich regions that resin has failed to infiltrate, and are the locations where degradation of the HL occurs over time [50]. In the present study, the three-step etch-and-rinse adhesive OFL had lower nanoleakage scores compared with the SBU universal adhesive. Three-step etch-and-rinse adhesives contain a lower percentage of hydrophilic resin monomers compared to two-step etch-and-rinse and one-step self-etch adhesives. This implies that three-step adhesive systems produce less permeable resin-dentine interfaces after in situ polymerization, and, hence, lower nanoleakage expression [55-57]. When Ch solution was used as an additional primer with OFL, it may have increased the hydrophilic properties of the adhesive system, providing a more porous HL. Regardless of the bonding system employed and the number of steps required for its application, all adhesive systems examined exhibited variable degrees of incomplete polymerization [57-59].

The results of the present study confirm that MMP activation is induced by both etch-and-rinse and universal adhesives, although higher levels of activity were detected for the etch-and-rinse adhesive. The etching step of the etch-and-rinse adhesives exposes a more apatite-depleted collagen dentine matrix than self-etch adhesives [1]. In addition, collagen matrices exposed by self-etched adhesives are partially protected by intrafibrillar apatite crystallites. Hence, more extensive MMP activation is expected with the use of etch-and-rinse adhesives [60]. The activity induced by OFL and SBU was not completely inhibited after $\mathrm{Ch}$ application, despite the observation that $\mathrm{Ch}$ was able to inactivate MMP activity on mineralized and demineralized dentine powder.

Apart from increasing the collagen stiffness through the creation of interfibrillar and intrafibrillar cross-links, the inactivation of endogenous MMPs may also be a property of the cross-linking agents $[12,20,21,61,62]$. Cross-linking agents inactivate dentine MMPs exposed by acid demineralization by altering the 3-D conformation of the catalytic domains of those enzymes, preventing them from actively interacting with the collagen substrate [54]. Despite previous studies demonstrating that the use of $\mathrm{Ch}$ with carbodiimide, N-hydroxysuccinimide, and riboflavin improves the resistance of dentine surface collagen to enzymatic degradation, this effect could not be identified $[30,63,64]$. The present study is the first one to use Ch solution as a dentine primer without incorporating the polymer with other cross-linking agents. The inability of $\mathrm{Ch}$ solution to reduce endogenous protease activity in the adhesive groups may be attributed to (1) undesirable interaction between the adhesive systems with $\mathrm{Ch}$ that may have compromised the function of $\mathrm{Ch}$ as a cross-linking agent; and (2) Ch, when used alone, is a weak cross-linker, because it only inhibits MMPs when applied on mineralized and demineralized dentine without adhesive systems. The initial cross-linking effect of $\mathrm{Ch}$ is probably futile when the pro-forms of the MMPs are activated to their active forms by acidic adhesive resin monomers. Further in vivo studies should clarify the role $\mathrm{Ch}$ in stabilizing the adhesive interface.

\section{Materials and Methods}

\subsection{Microtensile Bond Strength ( $\mu$ TBS)}

Sixty recently extracted human molars were sectioned with a slow-speed diamond blade (Isomet 5000, Buehler Ltd., Lake Buff, IL, USA), under water cooling, into 4-mm-thick dentine discs comprising deep coronal dentine. A standardized smear layer was created with 600-grit silicon carbide paper (Buehler Ltd.). The specimens were divided into 4 experimental groups $(n=10)$ according to the type of adhesive system and whether $0.1 \%$ Ch was employed for dentine pretreatment: Group 1: 
OFL ( $n=10)$ : Dentine was etched for 15 seconds with $37.5 \%$ phosphoric-acid gel (Kerr, Orange, CA, USA) and rinsed with water. Acid-etched dentine was primed and bonded with Optibond FL (Kerr) following the manufacturer's instructions; Group 2: OFL-Ch $(n=10)$ : Dentine was etched as for group 1 . Acid-etched dentine was pretreated with $0.1 \% \mathrm{Ch}$ water-solution for $1 \mathrm{~min}$ and air-dried for $5 \mathrm{~s}$. The Ch-treated dentine was subsequently primed and bonded with Optibond FL; Group 3: SBU $(n=10)$ : Scotchbond Universal (3M ESPE, St. Paul, MN, USA) was applied in self-etch mode on mineralized dentine according to the manufacturer's instructions; Group 4: SBU-Ch $(n=10)$ : Mineralized dentine was treated with $0.1 \% \mathrm{Ch}$ for $1 \mathrm{~min}$ and air-dried for 5 seconds. Scotchbond Universal adhesive was then applied as for group 3.

Two-millimeter-thick layers of a nanofilled resin composite (Filtek Supreme XTE, 3M ESPE, St. Paul, MN, USA) were placed and light-cured for 40 seconds (Elipar, 3M ESPE, St. Paul, MN, USA). The teeth were either stored in artificial saliva for $24 \mathrm{~h}[11](n=5 ; \mathrm{T} 0)$ or thermocycled $(n=5 ; \mathrm{T} 1 ; 10,000$ cycles; $5^{\circ} \mathrm{C} / 55^{\circ} \mathrm{C}, 30 \mathrm{~s}$ of exposure time) before microtensile testing. Resin-dentine sticks were made with cross-sectional areas of $0.8 \mathrm{~mm} \times 0.8 \mathrm{~mm}$ from each bonded tooth, using a low-speed saw with water cooling. Each stick had its dimension measured with a pair of digital calipers $( \pm 0.01 \mathrm{~mm})$ and was stressed to failure using a simplified universal testing (Instron 3345, Instron Corp., Canton, MA, USA) at a crosshead speed of $1 \mathrm{~mm} / \mathrm{min}$. Failure mode was evaluated using a stereomicroscope (SZX7, Olympus Inc., Hamburg, Germany) at 30× magnification and classified as adhesive (A), cohesive in composite (CC), cohesive in dentine (CD), or mixed (M) failures. Statistical analysis was performed by two-way analysis of variance to examine the effects of adhesive treatment and thermocycling, and the interaction of these two factors on bond strength. Post-hoc pairwise comparisons were performed using the Tukey test. For all analyses, statistical significance was set at $\alpha=0.05$.

\subsection{Interfacial Nanoleakage}

At baseline (T0) or after thermocycling (T1), 2 sticks from each tooth prepared for the microtensile testing were selected for nanoleakage evaluation $(n=5)$. Specimens were covered with nail varnish, leaving $1 \mathrm{~mm}$ of dentine or resin composite exposed on either side of the bonded interface. The varnished-covered specimens were immersed in $50 \mathrm{wt} \%$ ammoniacal silver nitrate for $24 \mathrm{~h}$ at $37^{\circ} \mathrm{C}$ in a light-proof container [65]. After $24 \mathrm{~h}$, the specimens were rinsed with distilled water for $1 \mathrm{~min}$ and immersed in a photodeveloping solution for 8 hours under a fluorescent light to reduce silver ions into metallic silver grain within voids along the bonded interfaces. The sticks were polished under water, with 600 grit $\mathrm{SiC}$ discs, to remove the varnish coats and were embedded in transparent chemically cure epoxy resin (Epoxycure, Buehler Ltd., Lake Bluff, IL, USA). The embedded specimens were reduced to half of its thickness with $\mathrm{SiC}$ discs and the exposed surface was mechanically polished with a wet \# 600, 800, 1200, and 4000 grit SiC discs (Buehler Ltd., Lake Bluff, IL, USA). Thereafter, the specimens were ultrasonically cleaned for 5 minutes, air dried, and mounted on stubs. Resin-dentine interfaces were analyzed by a field emission scanning electron microscope operated in the backscattered mode (Phillips XL30 ESEM, FEI Company, Hillsboro, OR, USA). The extent of interfacial nanoleakage along the resin interface was scored on a 4-point scale by two observers: $0 \%-25 \%$ nanoleakage, $25 \%-50 \%$ nanoleakage, $50 \%-75 \%$ nanoleakage, and $75 \%-100 \%$ nanoleakage. Representative specimens were coated with carbon (Bal-Tec Sputter Coater SCD 005, Bal-Tec GmbH, Witten, Germany) and examined using a scanning electron microscope (UHR Nova NanoSEM 230, FEI Company, Hillsboro, OR, USA).

Nanoleakage scores in the 4 subgroups were arranged into four $2 \times 4$ contingency table and analyzed with the Fisher-Freeman-Halton statistic [66].

\subsection{Zymography of Dentine Extracts}

Zymographic was performed according to Mazzoni et al. [60]. Mineralized dentine powder was obtained from an additional 12 humans' third molars after freezing the dentine in liquid nitrogen and triturating the frozen mineralized dentine chips using a Retsch mill (Model MM400, Retsch GmbH, Haan, Germany). Aliquots of mineralized dentine powder were divided into 8 groups (Table 1): 
- $\quad$ Group 1 (Lane 1-MP): Untreated mineralized dentine powder (MP; control).

- Group 2 (Lane 2-MP + Ch): MP was treated with $0.1 \% \mathrm{Ch}$ for $30 \mathrm{~min}$.

- Group 3 (Lane 3-DP): MP treated with $1 \mathrm{~mL}$ of $10 \mathrm{wt} \%$ phosphoric acid for $10 \mathrm{~min}$ and used as demineralized control (DP).

- Group 4 (Lane 4-DP + Ch): DP was treated with $0.1 \% \mathrm{Ch}$ for $30 \mathrm{~min}$.

- Group 5 (Lane 5-OFL): DP was mixed with $100 \mu \mathrm{L}$ of Optibond FL (OFL).

- Group 6 (Lane 6-OFL + Ch): DP was treated with $0.1 \%$ Ch and then mixed with $100 \mu \mathrm{L}$ of OFL.

- Group 7 (Lane 7-SBU): MP was mixed with $100 \mu \mathrm{L}$ of Scotchbond Universal (SBU).

- Group 8 (Lane 8-SBU + Ch): MP was mixed with $0.1 \% \mathrm{Ch}$ and then mixed with $100 \mu \mathrm{L}$ of SBU.

For the adhesive groups, $1 \mathrm{~mL}$ of acetone was used to extract the adhesive from the treated dentine powder. The extract was subsequently centrifuged $(20,800 \times g$ for $20 \mathrm{~min})$, re-suspended in acetone, and re-centrifuged 2 more times for the removal of additional unpolymerized comonomers.

Dentine powder aliquots were re-suspended in extraction buffer $(50 \mathrm{mM}$ Tris- $\mathrm{HCl}, \mathrm{pH} 6$, containing $5 \mathrm{mM} \mathrm{CaCl} 2,100 \mathrm{mM} \mathrm{NaCl}, 0.1 \%$ Triton X-100, 0.1\% non-ionic detergent P-40, $0.1 \mathrm{mM} \mathrm{ZnCl}$, $0.02 \% \mathrm{NaN}_{3}$ ) for $24 \mathrm{~h}$ at $4{ }^{\circ} \mathrm{C}$. The mixture was sonicated intermittently for 10 minutes (ca. $\approx 30$ pulses), and centrifuged for $20 \mathrm{~min}$ at $4{ }^{\circ} \mathrm{C}(12,000 \mathrm{rpm})$. The supernatant was removed and re-centrifuged. The protein content was concentrated using a centrifugal concentrator (Vivaspin 500, 10,000kDa cut off; Sartorius Stedim Biotech, Goettingen, Germany) for $30 \mathrm{~min}$ at $4{ }^{\circ} \mathrm{C}(10,000 \mathrm{rpm}$ for 3 times). Total protein concentration was determined using the Bradford assay (Bio-Rad, Hercules, CA, USA) with a spectrophotometer. Dentine protein aliquots $(60 \mu \mathrm{g})$ were diluted in Laemmli sample buffer in a 4:1 ratio. Sodium dodecyl sulfate-polyacrylamide gel electrophoresis (SDS-PAGE) was then performed in plates containing $1 \mathrm{mg} / \mathrm{mL}$ fluorescein-labelled gelatine. Pre-stained low-range molecular-weight SDS-PAGE standards (Bio-Rad) were used as molecular-weight markers. After electrophoresis, the gels were rinsed for $1 \mathrm{~h}$ in $2 \%$ Triton $\mathrm{X}-100$ and incubated in zymography activation buffer $(50 \mathrm{mmol} / \mathrm{L}$ Tris- $\mathrm{HCl}, 5 \mathrm{mmol} / \mathrm{L} \mathrm{CaCl}_{2}, \mathrm{pH} 7.4$ ) for $48 \mathrm{~h}$. Proteolytic activities were recorded using a long-wave ultraviolet light scanner (ChemiDoc Universal Hood, Bio-Rad).

\section{Conclusions}

Within the limitations of the present study (i.e., in vitro), it may be concluded that the use of $0.1 \%$ Ch solution as an additional primer does not influence the durability or bond strength of the resin-dentine bond over time, as applied to the etch-and-rinse and self-etch adhesives examined. Dentine collagen cross-linking produced by $\mathrm{Ch}$ appears to be efficient only when adhesives are not used. Further studies are required to fully understand the cross-linking of $\mathrm{Ch}$ with dentine and its possible interaction with adhesive systems.

Author Contributions: Conceptualization and design of the study, L.B., A.M. and L.C.; Investigation, E.B., S.R.C. and F.P.; Formal analysis A.C., T.M., G.A.-B. and F.R.T.; writing-original draft preparation, E.B., S.R.C., T.M., A.C. and F.P.; writing-review and editing, G.A.-B., L.C., F.R.T., L.B. and A.M.; funding acquisition, E.B. All authors have read and agreed to the published version of the manuscript.

Funding: This research was supported by the European Federation of Conservative Dentistry.

Conflicts of Interest: The authors declare no conflict of interest. The funders had no role in the design of the study; in the collection, analyses, or interpretation of data; in the writing of the manuscript, or in the decision to publish the results.

\section{References}

1. Breschi, L.; Maravic, T.; Cunha, S.R.; Comba, A.; Cadenaro, M.; Tjäderhane, L.; Pashley, D.H.; Tay, F.R.; Mazzoni, A. Dentin bonding systems: From dentin collagen structure to bond preservation and clinical applications. Dent. Mater. 2018, 34, 78-96. [CrossRef] [PubMed]

2. Nakabayashi, N.; Nakamura, M.; Yasuda, N. Hybrid layer as a dentin-bonding mechanism. J. Esthet. Dent. 1991, 3, 133-138. [CrossRef] [PubMed] 
3. Nakabayashi, N. The hybrid layer: A resin-dentin composite. Proc. Finn. Dent. Soc. 1992, 88, 321-329. [PubMed]

4. Mazzoni, A.; Angeloni, V.; Comba, A.; Maravic, T.; Cadenaro, M.; Tezvergil-Mutluay, A.; Pashley, D.H.; Tay, F.R.; Breschi, L. Cross-linking effect on dentin bond strength and MMPs activity. Dent. Mater. 2018, 34, 288-295. [CrossRef]

5. Nakabayashi, N.; Kojima, K.; Masuhara, E. The promotion of adhesion by the infiltration of monomers into tooth substrates. J. Biomed. Mater. Res. 1982, 16, 265-273. [CrossRef]

6. Mazzoni, A.; Nascimento, F.; Carrilho, M.; Tersariol, I.; Papa, V.; Tjaderhane, L.; Di Lenarda, R.; Tay, F.; Pashley, D.; Breschi, L. MMP activity in the hybrid layer detected with in situ zymography. J. Dent. Res. 2012, 91, 467-472. [CrossRef]

7. Tjäderhane, L.; Larjava, H.; Sorsa, T.; Uitto, V.-J.; Larmas, M.; Salo, T. The activation and function of host matrix metalloproteinases in dentin matrix breakdown in caries lesions. J. Dent. Res. 1998, 77, 1622-1629. [CrossRef]

8. Sulkala, M.; Wahlgren, J.; Larmas, M.; Sorsa, T.; Teronen, O.; Salo, T.; Tjäderhane, L. The effects of MMP inhibitors on human salivary MMP activity and caries progression in rats. J. Dent. Res. 2001, 80, 1545-1549. [CrossRef]

9. Sulkala, M.; Larmas, M.; Sorsa, T.; Salo, T.; Tjäderhane, L. The localization of matrix metalloproteinase-20 (MMP-20, enamelysin) in mature human teeth. J. Dent. Res. 2002, 81, 603-607. [CrossRef]

10. Boushell, L.W.; Kaku, M.; Mochida, Y.; Bagnell, R.; Yamauchi, M. Immunohistochemical localization of matrixmetalloproteinase-2 in human coronal dentin. Arch. Oral Biol. 2008, 53, 109-116. [CrossRef]

11. Pashley, D.; Tay, F.; Yiu, C.; Hashimoto, M.; Breschi, L.; Carvalho, R. Collagen degradation by host-derived enzymes during aging. J. Dent. Res. 2004, 83, 216-221. [CrossRef] [PubMed]

12. Mazzoni, A.; Pashley, D.H.; Nishitani, Y.; Breschi, L.; Mannello, F.; Tjäderhane, L.; Toledano, M.; Pashley, E.L.; Tay, F.R. Reactivation of inactivated endogenous proteolytic activities in phosphoric acid-etched dentine by etch-and-rinse adhesives. Biomaterials 2006, 27, 4470-4476. [CrossRef] [PubMed]

13. Nishitani, Y.; Yoshiyama, M.; Wadgaonkar, B.; Breschi, L.; Mannello, F.; Mazzoni, A.; Carvalho, R.M.; Tjäderhane, L.; Tay, F.R.; Pashley, D.H. Activation of gelatinolytic/collagenolytic activity in dentin by self-etching adhesives. Eur. J. Oral Sci. 2006, 114, 160-166. [CrossRef] [PubMed]

14. Tjäderhane, L.; Nascimento, F.D.; Breschi, L.; Mazzoni, A.; Tersariol, I.L.S.; Geraldeli, S.; Tezvergil-Mutluay, A.; Carrilho, M.R.; Carvalho, R.M.; Tay, F.R.; et al. Optimizing dentin bond durability: Control of collagen degradation by matrix metalloproteinases and cysteine cathepsins. Dent. Mater. 2013, 29, 116-135. [CrossRef]

15. Hebling, J.; Pashley, D.H.; Tjäderhane, L.; Tay, F.R. Chlorhexidine arrests subclinical degradation of dentin hybrid layers in vivo. J. Dent. Res. 2005, 84, 741-746. [CrossRef]

16. Castellan, C.S.; Bedran-Russo, A.K.; Karol, S.; Pereira, P.N.R. Long-term stability of dentin matrix following treatment with various natural collagen cross-linkers. J. Mech. Behav. Biomed. Mater. 2011, 4, 1343-1350. [CrossRef]

17. Castellan, C.S.; Bedran-Russo, A.K.; Antunes, A.; Pereira, P.N.R. Effect of dentin biomodification using naturally derived collagen cross-linkers: One-year bond strength study. Int. J. Dent. 2013, 2013, 918010. [CrossRef]

18. Liu, Y.; Tjäderhane, L.; Breschi, L.; Mazzoni, A.; Li, N.; Mao, J.; Pashley, D.H.; Tay, F.R. Limitations in bonding to dentin and experimental strategies to prevent bond degradation. J. Dent. Res. 2011,90,953-968. [CrossRef]

19. Mazzoni, A.; Angeloni, V.; Apolonio, F.M.; Scotti, N.; Tjäderhane, L.; Tezvergil-Mutluay, A.; Di Lenarda, R.; Tay, F.R.; Pashley, D.H.; Breschi, L. Effect of carbodiimide (EDC) on the bond stability of etch-and-rinse adhesive systems. Dent. Mater. 2013, 29, 1040-1047. [CrossRef]

20. Maravic, T.; Breschi, L.; Comba, A.; Cunha, S.R.; Angeloni, V.; Nucci, C.; Hebling, J.; Pashley, D.; Tay, F.; Mazzoni, A. Experimental use of an acrolein-based primer as collagen cross-linker for dentine bonding. J. Dent. 2017, 68, 85-90. [CrossRef]

21. Seseogullari-Dirihan, R.; Apollonio, F.; Mazzoni, A.; Tjaderhane, L.; Pashley, D.; Breschi, L.; Tezvergil-Mutluay, A. Use of crosslinkers to inactivate dentin MMPs. Dent. Mater. 2016, 32, 423-432. [CrossRef] [PubMed]

22. Husain, S.; Al-Samadani, K.H.; Najeeb, S.; Zafar, M.S.; Khurshid, Z.; Zohaib, S.; Qasim, S.B. Chitosan biomaterials for current and potential dental applications. Materials 2017, 10, 602. [CrossRef] [PubMed] 
23. Qasim, S.B.; Zafar, M.S.; Najeeb, S.; Khurshid, Z.; Shah, A.H.; Husain, S.; Rehman, I.U. Electrospinning of chitosan-based solutions for tissue engineering and regenerative medicine. Int. J. Mol. Sci. 2018, 19 , E407. [CrossRef]

24. Ali, S.; Sangi, L.; Kumar, N.; Kumar, B.; Khurshid, Z.; Zafar, M.S. Evaluating antibacterial and surface mechanical properties of chitosan modified dental resin composites. Technol. Health Care. 2020, 28, 165-173. [CrossRef] [PubMed]

25. Muzzarelli, R.A.A.; El Mehtedi, M.; Mattioli-Belmonte, M. Emerging biomedical applications of nano-chitins and nano-chitosans obtained via advanced eco-friendly technologies from marine resources. Mar. Drugs 2014, 12, 5468-5502. [CrossRef]

26. Farea, M.; Husein, A.; Halim, A.S.; Abdullah, N.A.; Mokhtar, K.I.; Lim, C.K.; Berahim, Z.; Mokhtar, K. Synergistic effects of chitosan scaffold and TGF $\beta 1$ on the proliferation and osteogenic differentiation of dental pulp stem cells derived from human exfoliated deciduous teeth. Arch. Oral. Biol. 2014, 59, 1400-1411. [CrossRef]

27. Ghimire, N.; Foss, B.L.; Sun, Y.; Deng, Y. Interactions among osteoblastic cells, Staphylococcus aureus, and chitosan-immobilized titanium implants in a postoperative coculture system: An in vitro study. J. Biomed. Mater. Res. A 2016, 104, 586-594. [CrossRef]

28. Shrestha, A.; Kishen, A. The Effect of Tissue Inhibitors on the Antibacterial Activity of Chitosan Nanoparticles and Photodynamic Therapy. J. Endod. 2012, 38, 1275-1278. [CrossRef]

29. Cicciù, M.; Fiorillo, L.; Cervino, G. Chitosan use in dentistry: A systematic review of recent clinical studies. Mar. Drugs 2019, 17, 417. [CrossRef]

30. Kishen, A.; Shrestha, S.; Shrestha, A.; Cheng, C.; Goh, C. Characterizing the collagen stabilizing effect of crosslinked chitosan nanoparticles against collagenase degradation. Dent. Mater. 2016, 32, 968-977. [CrossRef]

31. Wang, X.H.; Li, D.P.; Wang, W.J.; Feng, Q.L.; Cui, F.Z.; Xu, Y.X.; Song, X.H.; van der Werf, M. Crosslinked collagen/chitosan matrix for artificial livers. Biomaterials 2003, 24, 3213-3220. [CrossRef]

32. Madhavan, K.; Belchenko, D.; Motta, A.; Tan, W. Evaluation of composition and crosslinking effects on collagen-based composite constructs. Acta Biomater. 2010, 6, 1413-1422. [CrossRef] [PubMed]

33. Elsaka, S.; Elnaghy, A. Effect of addition of chitosan to self-etching primer: Antibacterial activity and push-out bond strength to radicular dentin. J. Biomed. Res. 2012, 26, 288-294. [CrossRef]

34. Diolosà, M.; Donati, I.; Turco, G.; Cadenaro, M.; Di Lenarda, R.; Breschi, L.; Paoletti, S. Use of methacrylate-modified chitosan to increase the durability of dentine bonding systems. Biomacromolecules 2014, 15, 4606-4613. [CrossRef] [PubMed]

35. Fawzy, A.; Nitisusanta, L.; Iqbal, K.; Daood, U.; Beng, L.T.; Neo, J. Characterization of riboflavin-modified dentin collagen matrix. J. Dent. Res. 2012, 91, 1049-1054. [CrossRef] [PubMed]

36. Shimokawa Ki, K.; Katayama, M.; Matsuda, Y.; Takahashi, H.; Hara, I.; Sato, H.; Kaneko, S. Matrix metalloproteinase (MMP)-2 and MMP-9 activities in human seminal plasma. Mol. Hum. Reprod. 2002, 8, 32-36. [CrossRef]

37. Bowes, J.H.; Cater, C.W. The interaction of aldehydes with collagen. Biochim. Biophys. Acta Protein Struct. 1968, 168, 341-352. [CrossRef]

38. Sung, H.; Chang, Y.; CT, C.; Chen, C.; Liang, H. Crosslinking characteristics and mechanical properties of a bovine pericardium fixed with a naturally occurring crosslinking agent. J. Biomed. Mater. Res. 1999, 47, 116-126. [CrossRef]

39. Macedo, G.V.; Yamauchi, M.; Bedran-Russo, A.K. Effects of chemical cross-linkers on caries-affected dentin bonding. J. Dent. Res. 2009, 88, 1096-1100. [CrossRef]

40. Gendler, E.; Gendler, S.; Nimni, M.E. Toxic reactions evoked by glutaraldehyde-fixed pericardium and cardiac valve tissue bioprosthesis. J. Biomed. Mater. Res. 1984, 18, 727-736. [CrossRef]

41. Hass, V.; Luque-Martinez, I.V.; Gutierrez, M.F.; Moreira, C.G.; Gotti, V.B.; Feitosa, V.P.; Koller, G.; Otuki, M.F.; Loguercio, A.D.; Reis, A. Collagen cross-linkers on dentin bonding: Stability of the adhesive interfaces, degree of conversion of the adhesive, cytotoxicity and in situ MMP inhibition. Dent. Mater. 2015, 32, 732-741. [CrossRef] [PubMed]

42. Comba, A.; Scotti, N.; Mazzoni, A.; Maravic, T.; Ribeiro Cunha, S.; Michelotto Tempesta, R.; Carossa, M.; Pashley, D.H.; Tay, F.R.; Breschi, L. Carbodiimide inactivation of matrix metalloproteinases in radicular dentine. J. Dent. 2019, 82, 56-62. [CrossRef] [PubMed] 
43. Waidyasekera, K.; Nikaido, T.; Weerasinghe, D.S.; Ichinose, S.; Tagami, J. Reinforcement of dentin in self-etch adhesive technology: A new concept. J. Dent. 2009, 37, 604-609. [CrossRef] [PubMed]

44. Perdigão, J.; Kose, C.; Mena-Serrano, A.P.; De Paula, E.A.; Tay, L.Y.; Reis, A.; Loguercio, A.D. A new universal simplified adhesive: 18-month clinical evaluation. Oper. Dent. 2014, 39, 113-127. [CrossRef]

45. Muñoz, M.; Luque-Martinez, I.; Malaquias, P.; Hass, V.; Reis, A.; Campanha, N.; Loguercio, A. In Vitro Longevity of Bonding Properties of Universal Adhesives to Dentin. Oper. Dent. 2015, 40, 282-292. [CrossRef]

46. Yoshida, Y.; Yoshihara, K.; Hayakawa, S.; Nagaoka, N.; Okihara, T.; Matsumoto, T.; Minagi, S.; Osaka, A.; Van Landuyt, K.; Van Meerbeek, B. HEMA inhibits interfacial nano-layering of the functional monomer MDP. J. Dent. Res. 2012, 91, 1060-5106. [CrossRef]

47. Yoshihara, K.; Yoshida, Y.; Nagaoka, N.; Fukegawa, D.; Hayakawa, S.; Mine, A.; Nakamura, M.; Minagi, S.; Osaka, A.; Suzuki, K.; et al. Nano-controlled molecular interaction at adhesive interfaces for hard tissue reconstruction. Acta Biomater. 2010, 6, 3573-3582. [CrossRef]

48. Yoshida, Y.; Yoshihara, K.; Nagaoka, N.; Hayakawa, S.; Torii, Y.; Ogawa, T.; Osaka, A.; Meerbeek, B. Van Self-assembled Nano-layering at the Adhesive interface. J. Dent. Res. 2012, 91, 376-381. [CrossRef]

49. Tian, F.; Zhou, L.; Zhang, Z.; Niu, L.; Zhang, L.; Chen, C.; Zhou, J.; Yang, H.; Wang, X.; Fu, B.; et al. Paucity of Nanolayering in Resin-Dentin Interfaces of MDP-based Adhesives. J. Dent. Res. 2016, 95, 380-387. [CrossRef]

50. Kim, Y.K.; Mai, S.; Mazzoni, A.; Liu, Y.; Tezvergil-Mutluay, A.; Takahashi, K.; Zhang, K.; Pashley, D.H.; Tay, F.R. Biomimetic remineralization as a progressive dehydration mechanism of collagen matrices-implications in the aging of resin-dentin bonds. Acta Biomater. 2010, 6, 3729-3739. [CrossRef]

51. Sadek, F.T.; Calheiros, F.C.; Cardoso, P.E.C.; Kawano, Y.; Tay, F.; Ferrari, M. Early and 24-hour bond strength and degree of conversion of etch-and-rinse and self-etch adhesives. Am. J. Dent. 2008, 21, 30-34. [PubMed]

52. Suh, B.I.; Feng, L.; Pashley, D.H.; Tay, F.R. Factors contributing to the incompatibility between simplified-step adhesives and chemically-cured or dual-cured composites. Part III. Effect of acidic resin monomers. J. Adhes. Dent. 2003, 5, 267-282. [PubMed]

53. Tay, F.R.; Hashimoto, M.; Pashley, D.H.; Peters, M.C.; Lai, S.C.N.; Yiu, C.K.Y.; Cheong, C. Aging affects two modes of nanoleakage expression in bonded dentin. J. Dent. Res. 2003, 82, 537-541. [CrossRef] [PubMed]

54. Pashley, D.H.; Tay, F.R.; Breschi, L.; Tjäderhane, L.; Carvalho, R.M.; Carrilho, M.; Tezvergil-Mutluay, A. State of the art etch-and-rinse adhesives. Dent. Mater. 2011, 27, 1-16. [CrossRef]

55. Tay, F.R.; Pashley, D.H. Dental adhesives of the future. J. Adhes Dent. 2002, 4, 91-103.

56. Tay, F.R.; Pashley, D.H.; Suh, B.I.; Carvalho, R.M.; Itthagarun, A. Single-step adhesives are permeable membranes. J. Dent. 2002, 30, 371-382. [CrossRef]

57. Breschi, L.; Mazzoni, A.; Ruggeri, A.; Cadenaro, M.; Di Lenarda, R.; De Stefano Dorigo, E. Dental adhesion review: Aging and stability of the bonded interface. Dent. Mater. 2008, 24, 90-101. [CrossRef] [PubMed]

58. Cadenaro, M.; Antoniolli, F.; Sauro, S.; Tay, F.R.; Di Lenarda, R.; Prati, C.; Biasotto, M.; Contardo, L.; Breschi, L. Degree of conversion and permeability of dental adhesives. Eur. J. Oral Sci. 2005, 113, 525-530. [CrossRef]

59. Cadenaro, M.; Maravic, T.; Comba, A.; Mazzoni, A.; Fanfoni, L.; Hilton, T.; Ferracane, J.; Breschi, L. The role of polymerization in adhesive dentistry. Dent. Mater. 2018, 35, e1-e22. [CrossRef]

60. Mazzoni, A.; Scaffa, P.; Carrilho, M.; Tjäderhane, L.; Di Lenarda, R.; Polimeni, A.; Tezvergil-Mutluay, A.; Tay, F.R.; Pashley, D.H.; Breschi, L. Effects of etch-and-rinse and self-etch adhesives on dentin MMP-2 and MMP-9. J. Dent. Res. 2013, 92, 82-86. [CrossRef]

61. Mazzoni, A.; Apolonio, F.M.; Saboia, V.P.A.; Santi, S.; Angeloni, V.; Checchi, V.; Curci, R.; Di Lenarda, R.; Tay, F.R.; Pashley, D.H.; et al. Carbodiimide inactivation of MMPs and effect on dentin bonding. J. Dent. Res. 2014, 93, 263-268. [CrossRef]

62. Seseogullari-Dirihan, R.; Mutluay, M.M.; Vallittu, P.; Pashley, D.H.; Tezvergil-Mutluay, A. Effect of pretreatment with collagen crosslinkers on dentin protease activity. Dent. Mater. 2015, 31, 941-947. [CrossRef] [PubMed]

63. Fawzy, A.S.; Nitisusanta, L.I.; Iqbal, K.; Daood, U.; Beng, L.T.; Neo, J. Chitosan/Riboflavin-modified demineralized dentin as a potential substrate for bonding. J. Mech. Behav. Biomed. Mater. 2012, 17, 278-289. [CrossRef] [PubMed]

64. Daood, U.; Iqbal, K.; Nitisusanta, L.I.; Fawzy, A.S. Effect of chitosan/riboflavin modification on resin/dentin interface: Spectroscopic and microscopic investigations. J. Biomed. Mater. Res. Part A 2013, 101A, 1846-1856. [CrossRef] [PubMed] 
65. Tay, F.R.; Pashley, D.H.; Yoshiyama, M. Two modes of nanoleakage expression in single-step adhesives. J. Dent. Res. 2002, 81, 472-476. [CrossRef]

66. Lydersen, S.; Pradhan, V.; Senchaudhuri, P.; Laake, P. Choice of test for association in small sample unordered r x c tables. Stat. Med. 2007, 26, 4328-4343. [CrossRef]

(C) 2020 by the authors. Licensee MDPI, Basel, Switzerland. This article is an open access article distributed under the terms and conditions of the Creative Commons Attribution (CC BY) license (http://creativecommons.org/licenses/by/4.0/). 